\title{
Evaluation of plasma d-dimer level in patients with chronic urticaria
}

\begin{abstract}
Background: Urticaria is a common disease impacting negatively on multiple aspects of patients' lives. Acute urticaria is defined as the occurrence of wheals with or without angioedema for less than 6 weeks, whereas chronic urticaria is defined as the occurrence of wheals and pruritus anywhere on the body and/or angioedema occurring for 6 weeks or longer. D-dimer is a fibrin degradation product so it is a marker of thrombin activity and fibrin turnover and thus reflects both haemostasis and fibrinolysis. Recent findings showed that in outpatients with sever to moderate $\mathrm{CU}$, mean D-dimer plasma levels were significantly higher than in a group of age- and sex-matched normal controls.
\end{abstract}

Objectives: To evaluate plasma D-dimer correlation with chronic urticaria disease activity.

Settings: Dermatology outpatient clinic of Al Azhar University Hospital in Damietta (Egypt), tertiary referral center.

Subjects and methods: This study included 40 patients with chronic urticaria. They were recruited from dermatology outpatient clinic of Al-Azhar University Hospital in Damietta. All cases were subjected to complete history taking, general examination and dermatological examination was performed for all patients with emphasis to determine the site and the type of the lesion and the presence of any dermatological diseases, laboratory investigations including CBC, ESR, PT, PTT and D-dimer.

Results: In this study we found normal plasma D-dimer level in $(62.5 \%)$ of enrolled patients and elevated plasma D-dimer level in (37.5\%) of them. We also demonstrated that there was statistically significant positive correlation to clinical disease severity.

Conclusions: Investigation for plasma D-dimer level may be an alternative way to evaluate disease activity and severity in patients with CU.

Keywords: fibrin degradation product, d-dimer, tissue factor, urticaria, chronic urticaria

\section{Introduction}

Urticaria is a common disease impacting negatively on multiple aspects of patients' lives. The disease carries a significant emotional and economic burden for the patient and often results in an odyssey between doctors of different specialties. ${ }^{1}$ Urticaria is a cutaneous reaction characterized by a sudden pruritic eruption accompanied by erythema and edema that lasts for a few hours. According to its evolution over time, it can be classified as acute ( $<6$ weeks) or chronic ( $>6$ weeks). ${ }^{2} \mathrm{D}$-dimer is a fibrin degradation product. It is so named because it contains two $\mathrm{D}$ fragments of the fibrin protein joined together by a cross-link. ${ }^{3}$ Patients with severe CU show increase in plasma markers of thrombin generation and fibrinolysis due to expression of tissue factors by activated eosinophils. ${ }^{4}$ Thrombin increases vascular permeability, stimulates mast cell degranulation and may activate protease activated receptor 1 (PAR1) on mast cells. ${ }^{5}$ D-dimer has been proposed as an alternative way to evaluate disease severity in CU patients. ${ }^{6}$

\section{Material}

The study was carried out on forty adult patients with chronic urticaria recruited from the dermatology outpatient clinic of AlAzhar University Hospital in Damietta. All selected individuals were enrolled in the study after an informed consent obtained from all participants after taking the approval of Research Ethics Committee of the Faculty of Medicine Al Azhar University in Damietta.
Volume 3 Issue I - 2019

\author{
Hany Othman Abo Alwafa,' Mahmoud Farag \\ Mohammed, ${ }^{2}$ Yasmine Ramadan Mohammed ${ }^{3}$ \\ 'Department of Dermatology, Venereology \& Andrology, Al- \\ Azhar University, Egypt \\ ${ }^{2}$ Department of Clinical Pathology, Faculty of Medicine,Al-Azhar \\ University, Egypt \\ ${ }^{3}$ Dermatology resident at Sharq El Madina hospital, Miami, \\ Alexandria, Egypt
}
Correspondence: Hany Othman Abo Alwafa, Lecturer of Dermatology and Venerology, Department of Dermatology and Venerology, faculty of medicine,Al-Azhar University, Egypt Email Dr_hanyosI38@yahoo.com

Received: December 18, 2018 | Published: January 28, 2019
Exclusion criteria: Patients with underlying condition which would affect D-dimer level, including deep venous thrombosis, pulmonary embolism, Pregnancy, old age, internal malignancy, recent surgery and drugs.

\section{Methods}

\section{Full history taking}

Regarding the current condition including onset, course and duration of lesions; presence of pruritus, pain, flushing, burning and angioedema; association with, foods and drugs, presence of associated symptoms such as fever, abdominal pain and joint pain, Past history of medications; recent surgery or previous disease affecting D-dimer plasma level and response to treatment with antihistamines.

\section{Examination}

Complete general examination. Dermatological examination was performed for all patients with emphasis to determine the site and size of the lesion and the presence of any other dermatological disease. Assessment of disease severity according to Urticaria Activity Score was estimated according to number of wheals and pruritus per day.

\section{Routine investigations}

Complete blood count, prothrombin time, partial thromboplastin time and erythrocyte sedimentation rate were done. 


\section{D-dimer level evaluation}

Venous sampling: venous blood sample $2 \mathrm{ml}$ blood was taken under complete aseptic technique in sodium citrate tubes for estimation of D-dimer, PT and PTT. Plasma was separated by centrifugation at $1500 \mathrm{~g}$ for 15 minutes then stored at $4^{\circ} \mathrm{C}$ then sent to laboratory. Frozen plasma re centrifuged at $37^{\circ} \mathrm{C}$ then tested for the presence of D-dimer. D-dimer was processed using ELISA D-dimer kits.

\section{Statistical analysis}

Data were fed to the computer and analyzed using IBM SPSS software package version 20.0. (Armonk, NY: IBM Corp) Qualitative data were described using number and percent. The KolmogorovSmirnov test was used to verify the normality of distribution Quantitative data were described using range (minimum and maximum), mean, standard deviation and median. Significance of the obtained results was judged at the $5 \%$ level.

The tests used were: Chi-square test; for categorical variables, to compare between different groups; Fisher's Exact or Monte Carlo correction; correction for chi-square when more than $20 \%$ of the cells have expected counts less than 5 .

\section{Results}

The study included $34(35.0 \%)$ females and $6(15.0 \%)$ males. Their age ranged between 18 to 52years old with a mean \pm SD of $31.22 \pm 10.15$ years (Table 1) (Figure 1).

Table I Demographic data of the studied cases $(n=40)$

\begin{tabular}{lll}
\hline & No. & $\%$ \\
\hline Sex & & \\
Male & 6 & 15 \\
Female & 34 & 85 \\
Age (years) & \\
Min.-Max. & $18.0-52.0$ \\
Mean \pm SD. & $31.22 \pm 10.15$ \\
Median & 28.5 \\
\hline
\end{tabular}

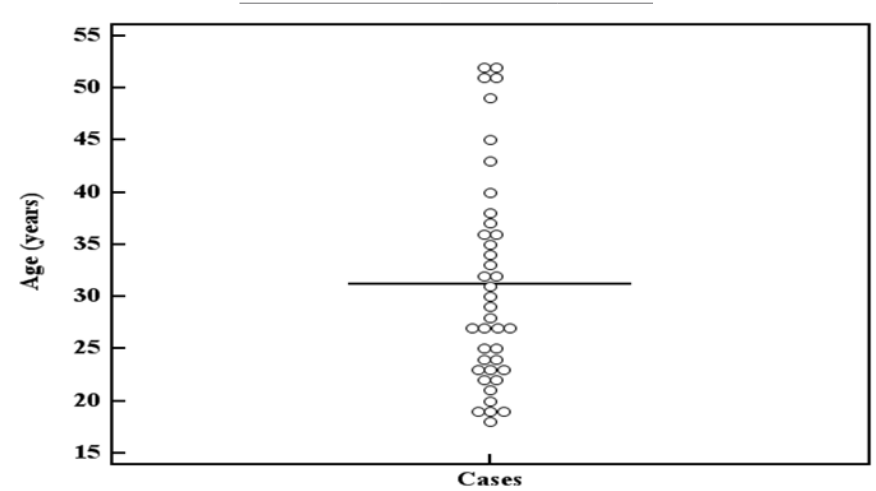

Figure I Distribution of the studied cases according to Age (years) $(n=40)$.

\section{Family history and duration of disease}

Family history of CU was found positive only in $1(2.5 \%)$ patient and negative in $39(97.5 \%)$ patients. Disease duration ranged between 6-48 months with a mean \pm SD of $15.35 \pm 11.31$ (Table 2) (Figure 2). Presence of angioedema and severity of disease (Table 3) (Table 4). Presence of associated symptoms and response to treatment (Table 5)
(Table 6). Routine laboratory investigations and D-dimer level (Table 7-10) (Figure 3) (Figure 4).

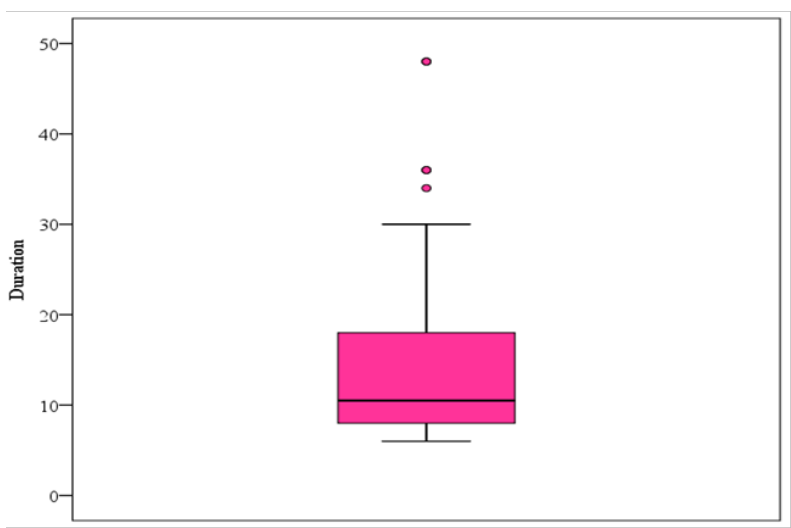

Figure 2 Distribution of the studied cases according to duration C. Presence of angioedema and severity of disease.

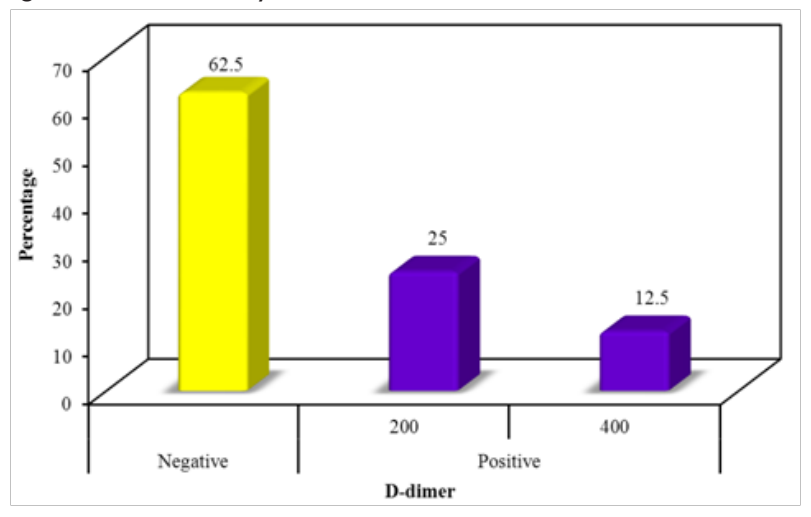

Figure 3 Distribution of the studied cases according to D-dimer level $(n=40)$.

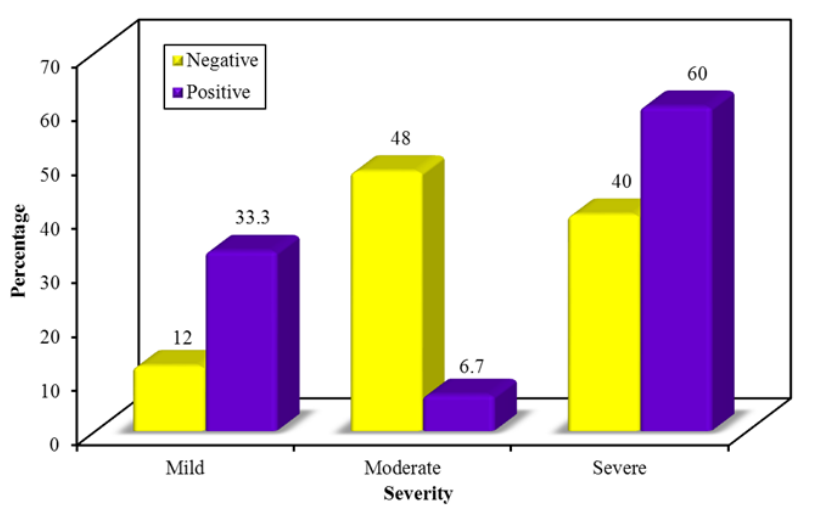

Figure 4 Relation between D-dimer and Severity.

Table 2 Distribution of the studied cases according to family history and duration of disease $(n=40)$

\begin{tabular}{lll}
\hline & No. & \% \\
\hline Family history & & \\
Negative & 39 & 97.5 \\
Positive & 1 & 2.5 \\
Duration & & \\
Min.-Max. & $6.0-48.0$ \\
Mean \pm SD. & $15.35 \pm 11.31$ \\
Median & 10.5 & \\
\hline
\end{tabular}


Table 3 Distribution of the studied cases according to severity $(n=40)$

\begin{tabular}{lll}
\hline Severity & No. & \% \\
\hline Mild & 8 & 20 \\
Moderate & 13 & 32.5 \\
Severe & 19 & 47.5
\end{tabular}

Table 4 Distribution of the studied cases according to presence of angioedema $(n=40)$

\begin{tabular}{lll}
\hline Angioedema & No. & \% \\
\hline Negative & 27 & 67.5 \\
Positive & 13 & 32.5
\end{tabular}

Table 5 Distribution of the studied cases according to associated symptoms $(n=40)$

\begin{tabular}{lll}
\hline Associated symptoms & No. & \% \\
\hline No & 21 & 52.5 \\
Yes & 19 & 47.5 \\
Abdominal pain & 7 & 17.5 \\
Fever & 5 & 12.5 \\
Headache & 6 & 15 \\
Joint pain & 6 & 15 \\
\hline
\end{tabular}

Table 6 Distribution of the studied cases according to response to treatment $(n=40)$

\begin{tabular}{lcc}
\hline Response to treatment & No. & $\%$ \\
\hline Non responder & 14 & 35 \\
Responder & 26 & 65
\end{tabular}

Table 7 Descriptive analysis of the studied cases according to lab, investigations $(n=40)$

\begin{tabular}{llll}
\hline & Min. - Max. & Mean \pm SD. & Median \\
\hline RBC & $3.80-5.50$ & $4.62 \pm 0.44$ & 4.7 \\
WBC & $4.60-11.30$ & $7.67 \pm 1.79$ & 7.7 \\
Platelets & $150.0-420.0$ & $272.75 \pm 85.82$ & 271.5 \\
PT & $10.80-14.0$ & $12.36 \pm 1.01$ & 12.35 \\
PTT & $25.0-35.0$ & $29.62 \pm 2.69$ & 30 \\
ESR & $5.0-28.0$ & $15.43 \pm 5.15$ & 14.5 \\
\hline
\end{tabular}

Table 8 Distribution of the studied cases according to elevated D-dimer level $(n=40)$

\begin{tabular}{lll}
\hline D-dimer & No. & \% \\
\hline Negative & 25 & 62.5 \\
Positive & 15 & 37.5 \\
200 & 10 & 25 \\
400 & 5 & 12.5
\end{tabular}

Table 9 Relation between D-dimer and different parameters

\begin{tabular}{|c|c|c|c|c|c|c|}
\hline & \multicolumn{4}{|c|}{ D-dimer } & \multirow{3}{*}{ c2 } & \multirow{3}{*}{$\mathbf{p}$} \\
\hline & \multicolumn{2}{|c|}{ Negative $(n=25)$} & \multicolumn{2}{|c|}{$\operatorname{Positive}(n=15)$} & & \\
\hline & No. & $\%$ & No. & $\%$ & & \\
\hline \multicolumn{7}{|l|}{ Severity } \\
\hline Mild & 3 & 12 & 5 & 33.3 & \multirow{3}{*}{$8.114^{*}$} & \multirow{3}{*}{${ }^{\mathrm{MC}} \mathrm{p}=0.016^{*}$} \\
\hline Moderate & 12 & 48 & 1 & 6.7 & & \\
\hline Severe & 10 & 40 & 9 & 60 & & \\
\hline \multicolumn{7}{|l|}{ Angioedema } \\
\hline Negative & 17 & 68 & 10 & 66.7 & \multirow{2}{*}{0.008} & \multirow{2}{*}{${ }^{\mathrm{FE}} \mathrm{p}=1.000$} \\
\hline Positive & 8 & 32 & 5 & 33.3 & & \\
\hline \multicolumn{7}{|c|}{ Response to treatment } \\
\hline Non responder & 8 & 32 & 6 & 40 & \multirow{2}{*}{0.264} & \multirow{2}{*}{0.608} \\
\hline Responder & 17 & 68 & 9 & 60 & & \\
\hline
\end{tabular}

$\chi 2$, Chi square test for comparing between the two categories

MCp, $\mathrm{p}$ value for Monte Carlo for Chi square test for comparing between the two categories

FEp, $p$ value for Fisher Exact for Chi square test for comparing between the two categories

*, Statistically significant at $\mathrm{p} \leq 0.05$.

Table I 0 Relation between positive D-dimer and different parameters $(n=15)$

\begin{tabular}{|c|c|c|c|c|c|c|}
\hline & \multicolumn{4}{|c|}{ D-dimer } & \multirow{3}{*}{$\mathrm{c} 2$} & \multirow{3}{*}{$\mathrm{p}$} \\
\hline & \multicolumn{2}{|c|}{$200(n=10)$} & \multicolumn{2}{|c|}{$400(n=5)$} & & \\
\hline & No. & $\%$ & No. & $\%$ & & \\
\hline \multicolumn{7}{|l|}{ Severity } \\
\hline Mild & 5 & 50 & 0 & 0 & \multirow[t]{3}{*}{4.576} & \\
\hline Moderate & 0 & 0 & 1 & 20 & & ${ }^{\mathrm{MC}} \mathrm{p}=0.125$ \\
\hline Severe & 5 & 50 & 4 & 80 & & \\
\hline \multicolumn{7}{|l|}{ Angioedema } \\
\hline Negative & 6 & 60 & 4 & 80 & \multirow{2}{*}{0.6} & \multirow{2}{*}{${ }^{\mathrm{FE}} \mathrm{p}=0.6$} \\
\hline Positive & 4 & 40 & 1 & 20 & & \\
\hline \multicolumn{7}{|c|}{ Response to treatment } \\
\hline Non responder & 4 & 40 & 2 & 40 & \multirow{2}{*}{0} & \multirow{2}{*}{${ }^{\mathrm{FE}} \mathrm{p}=1$} \\
\hline Responder & 6 & 60 & 3 & 60 & & \\
\hline
\end{tabular}

$\chi 2$, Chi square test for comparing between the two categories

MCp, $p$ value for Monte Carlo for Chi square test for comparing between the two categories

FEp, $p$ value for Fisher Exact for Chi square test for comparing between the two categories

Citation: Abo Alwafa, Mohammed MF, Mohammed YR. Evaluation of plasma d-dimer level in patients with chronic urticaria.J Dermat Cosmetol. 20 I9;3(I):7-II. 


\section{Discussion}

Urticaria is a common disease impacting negatively on multiple aspects of patients' lives. The disease carries a significant emotional and economic burden for the patient and often results in an odyssey between doctors of different specialties. ${ }^{1}$ The evaluation of disease severity and activity of chronic urticaria (CU) is essential for the adequate treatment of patients. However, there is no reliable biomarker for such evaluations. Recently, markers of blood coagulation and fibrinolysis have been revealed to be elevated in severe cases of CU. ${ }^{7}$ Patients with chronic urticaria (CU) frequently show increased mean D-dimer plasma levels. ${ }^{8}$ In this work we aimed to evaluate D-dimer plasma level among patients with chronic urticaria. This study included 40 patients with chronic urticaria. They were recruited from dermatology outpatient clinic of Al Azhar University Hospital in Damietta. In the present study the percentage of females presenting with CU was much higher than that of males as $(85 \%)$ of the patients were females. This is in agreement with Silvares et al. ${ }^{9}$ who conducted a study on CU that included ( $86 \%$ ) females.

Epidemiologically $\mathrm{CU}$ is known to be more frequent in females than in males but it is approximately twice as common in women as in men especially of middle age. However several studies in CU conducted their work on mostly female patients. ${ }^{10}$ Female patients with CU tend to have lower tolerance for their symptoms than males. $\mathrm{CU}$ has a higher psychological impact on female patients, causing frequent visits to the dermatology clinic, making them more likely to be picked in studies than males. The age of patients included in this study ranged from 18 to 52years with a mean age of 28.50years, however Triwongwaranat et al. ${ }^{6}$ conducted a study on CU patients with age from 16 to 73 years. In the present study, $(2.5 \%)$ of patients had a positive family history of CU. However Vazquez et al. ${ }^{11}$ reported that $(4 \%)$ of CIU patients had a positive family history affecting at least one first degree relative and suggested the existence of a genetic background for the disease.

In the present study, (32.5\%) of patients had a history of positive angioedema, similar to Sanchez et al. ${ }^{12}$ and Vazquez et al. ${ }^{11}$ Contrarily Silvares et al. ${ }^{9}$ and Sabroe et al. ${ }^{13}$ reported that angioedema occurred in $82 \%$ and $85 \%$ respectively of CSU patients. Such a high percentage may be explained by the longer duration of the study, with a mean of 6 years, or selection of severe cases. In the present study, (47.5\%) of patients had history of associated symptoms including fever, headache, abdominal pain and joint pain. This is in agreement with Krupashankar et al. ${ }^{14}$ who reported associated symptoms in the form of headache $(21.25 \%)$ throat pain $(8.75 \%)$, abdominal pain $(8.46 \%)$, vomiting (3.75\%) and fever (3.75\%).

In the current study, regarding response of patients to treatment $35 \%$ are non-responders to antihistamines and this is in agreement with Humphreys et al. ${ }^{15}$ and Gattey et al. ${ }^{16}$ On the other hand, Kaplan ${ }^{17}$ and Maurer et al. ${ }^{18}$ found that antihistamines are effective in treating $45 \%-60 \%$ of patients; the rest are refractory to treatment and achieve little or no benefit even from maximal doses. This contrast may be due to a higher percentage of severe cases in this study. In the current study, there wasn't an association between demographic data and plasma D-dimer level, and this is in agreement with Triwongwaranat et al. ${ }^{6}$

In this study we found normal plasma D-dimer level in $(62.5 \%)$ of enrolled patients and elevated plasma D-dimer level in (37.5\%) of them. This is in contrast with Triwongwaranat et al. ${ }^{6}$ who found elevated D-dimer levels in $(48.3 \%)$. This difference may be due to selection of more severe cases. The current study reveals lack of association between $\mathrm{D}$-dimer level and angioedema $(\mathrm{p}=1.000)$. The result was not verified in comparable studies in the literature. In the present study correlation between D-dimer plasma level and response to treatment was lacking ( $\mathrm{p}=0.608)$, this is in contrast with Asero $^{19}$ who found that D-dimer is a biomarker for antihistamine resistant chronic urticaria. This contrast may be due to selection of more severe cases. In the current study, plasma level of D-dimer was higher in patients of sever disease than those having mild disease, a similar result was noted by previous studies performed in Europe by Asero et al. ${ }^{20}$ and a similar study performed in Thai by Triwongwaranat et al. ${ }^{6}$

\section{Conclusion}

Patients with chronic urticaria (CU) shows elevated D-dimer plasma levels. There was a positive correlation between plasma D-dimer levels and the severity of chronic urticaria.

\section{Disclosure statement}

No conflict of interest and no financial sport nor sponsorship.

\section{Acknowledgments}

None.

\section{Conflicts of interest}

Authors declare that there is no conflicts of interest.

\section{References}

1. Baiardini I, Giardini A, Pasquali M, et al. Quality of life and patients' satisfaction in chronic urticaria and respiratory allergy. Allergy. 2003;58(7):621-623

2. Zuberbier T, Aberer W, Asero R, et al. The EAACI/GA (2) LEN/ EDF/WAO Guideline for the definition, classification, diagnosis, and management ofurticaria: the 2013 revision and update. Allergy. 2014;69(7):868-887

3. Adam SS, Key NS, Greenberg CS. D-dimer antigen: current concepts and future prospects. Blood. 2009;113(13):2878-2887.

4. Asero R. Plasma D-dimer levels and clinical response to ciclosporin in severe chronic spontaneous urticarial. J Allergy Clin Immunol. 2015;135(5):1401-1403.

5. Triwongwaranat D, Kulthanan K, Chularojanamontri L, et al. Correlation between plasma D-dimer levels and the severity of patients with chronic urticarial. J Asia Pac Allergy. 2013;3(2):100-105.

6. Tedeschi A, Kolkhir P, Asero R, et al. Chronic urticaria and coagulation: pathophysiological and clinical aspects. Allergy. 2014;69(6):83-91.

7. Takahagi S, Mihara S, Iwamoto K, et al. Coagulation/fibrinolysis and inflammation markers are associated with disease activity in patients with chronic urticaria. Allergy. 2010;65(5):649-656.

8. Asero R, Tedeschi A, Riboldi P, et al. Chronic urticaria: Adisease at a cross road between autoimmunity and coagulation. Autoimmun Rev. 2007;7(1):71-76.

9. Silvares MR, Coelho KI, Dalben I, et al. Sociodemographic and clinical charachtaristics,causal factors and evolution ofv a group of patients with chronic urticaria-angioedema. Sao Paulo Med J. 2007;125(5):281-285.

10. Caproni M, Giomi B, Volpi W, et al. Chronic idiopathic urticaria: infiltrating cells and related cytokines in autologous serum induced wheals. Clin Immunol. 2005;114(3):284-292. 
11. Vazquez NF. Chronic urticaria. Characteristics, diagnosis and treatment. Rev Alerg. 1992;39(3):46-50.

12. Sanchez-Borges M, Asero R, Ansotegui IJ, et al. Diagnosis and treatment of urticaria and angioedema: a worldwide perspective. World Allergy Organ J. 2012;5(11):125-147.

13. Sabroe RA, Fiebiger E, Francis DM, et al. Classification of antiFcepsilonRI and anti-IgE autoantibodies in chronic idiopathic urticaria and correlation with disease severity. J Allergy Clin Immunol. 2002;110(3):492-499.

14. Krupashankar DS, Shashikala K, Madala R. Clinical and investigative assessment of patient with positive versus negative autologous serum skin test: a study of 80 south Indian patients. Indian J Dermatol. 2012;57(6):434-438.
15. Humphreys F, Hunter JA. The characteristics of urticaria in 390 patients. Br J Dermatol. 1998;138(4):635-638.

16. Gattey N, Bahrani B, Hull PR. Chronic spontaneous urticaria: A questionnaire survey. J Cutan Med Surg. 2016;20(3):241-243.

17. Kaplan AP. Treatment of chronic spontaneous urticaria. Allergy Asthma Immunol Res. 2012;4(6):326-331.

18. Maurer M, Church MK, Goncalo M, et al. Mangment and treatment of chronic Urticaria (CU). J Eur Acad Dermatol Venereol. 2015;29(Suppl 3):16-32.

19. Asero R. D-dimer: Abiomarker for antihistamine resistant chronic urticaria. J Allergy Clin Immunol. 2013;132(4):983-986.

20. Asero R, Tedeschi A, Riboldi P, et al. Severe chronic urticaria is associated with elevated plasma levels of D-dimer. Allergy. 2008;63(2):176-180. 